\title{
Use of geoinformation systems in environmental monitoring
}

\author{
Olena Pomortseva, Sergiy Kobzan*, Andrey Yevdokimov, and Maksym Kukhar \\ National University of Urban Economy in Kharkiv, 17, Marshal Bazhanov Street, Kharkiv, 61002, Ukraine.
}

\begin{abstract}
The purpose of the study, the materials of which are outlined in this article, is to uncover current trends in the development of environmental monitoring and the tracking of anthropogenic environmental impacts. To achieve this goal, it is proposed to use geoinformation systems to perform environmental monitoring and control, using appropriate software. For this purpose ArcGis software was used which allows monitoring the state of the atmosphere, its pollution and other deviations from the norm. The research was conducted exemplified by nine districts of Kharkiv. As a result of computer geospatial analysis, models and maps of urban pollution have been developed. In general, the intellectual analysis of geostatic models of emission distribution in the city allowed identifying and classifying zones of high concentrations of pollution and comparing them with air quality data. Methods of geostatistics transformed the data from a discrete to a continuous form of representation. Further studies in this area may be related to the improvement of geostatistical data analysis and pollution distribution prediction methods. As an example, mathematical formulas were presented to determine the atmospheric pollution index and the true or predicted pollution index, which can be determined on the basis of the data obtained and represented by elements of the ArcGis software package in a discrete and continuous form.
\end{abstract}

\section{Problem statement}

The natural environment of Ukraine is contaminated with a large number of various toxic chemical elements and compounds. Under these conditions, the task of ensuring the environmental safety of the population is urgent.

In the implementation of environmental monitoring and environmental control, a common functional element is to conduct observations and evaluate the data obtained by some characteristics. In environmental control, the objects of observation are anthropogenic objects or economic activity as a whole. In the course of environmental control, the managerial influence on the observed object is exercised, in the case of environmental monitoring - obtaining objective environmental data, predicting possible changes in time and space under the influence of natural and anthropogenic factors. The task of observation is to monitor the state of the environment, detect and predict negative changes, and provide timely information in the established manner [1]. In this case, the detection of any deviations in the state of atmospheric air, surface water and soil is a signal for taking control actions to prevent environmental pollution.

Modern technologies allow us to identify environmental problems at the stage of their occurrence, thereby facilitating anthropogenic load on the environment. Significant experience has been accumulated in the world practice in the field of monitoring the harmful effects of human activity on the environment. [2]. At present, objective opportunities and needs for the implementation of various technical and technological measures - special information technologies in the field of ecology - have appeared in Ukraine [3].

The two main methods for tracking the impact on the environment and what is happening in it are monitoring and control. The main difference between them is the dynamism of the first and the static character of the second. The most interesting for analysis is monitoring, which, unlike control, provides more research opportunities and is not so cruel for its purposes. Static control and dynamic monitoring are only external characteristics. In fact, in both cases we are talking about special information technologies [3, 4].

Thus, the topicality of scientific developments in this field becomes clear. The purpose of this article is to reveal the current trends in the development of environmental monitoring and the monitoring of anthropogenic impact on the environment.

\section{Analysis of recent research and publications}

Modern technologies allow us to explore the environment and make decisions about actions to eliminate the negative consequences of human activity, or support and improve life.

This issue is being addressed both internationally and regionally.

\footnotetext{
* Corresponding author: s.kobzan@gmail.com
} 
Research [5] examines the effective use of state-ofthe-art technologies for monitoring air conditions using both specialized equipment and portable devices based on the Android operating system. This paper discusses the implementation of an air quality analysis system based on geoinformation systems.

The study [6, 7] proposes the use of specially designed mathematical software for the implementation of environmental monitoring, the task of which is to solve specific problems, taking into account the situation in a particular locality. And as a basis for the implementation of this mathematical apparatus is used geographical information systems.

Ukraine is one of the industrial-agricultural countries. Until recently, the share of heavy industry has been $60 \%$ of the country's gross domestic product, which is substantially higher than in Western European countries where the figure is about $35 \%$. It is heavy industry enterprises that form the main man-made burden on the environment. A significant part of industrial enterprises (more than $80 \%$ ) is located in cities and urban-type settlements. About $70 \%$ of the country's population lives here. There are 436 cities and 925 urban settlements in Ukraine. According to statistics, up to $90 \%$ of gaseous, liquid and solid wastes are generated in urban areas and about $10 \%$ in rural areas. Many cities of Ukraine are characterized by a difficult ecological situation, due to the presence and concentration of enterprises of ferrous and non-ferrous metallurgy, heat power industry, chemistry and petrochemistry, mining and cement plants. Such cities are the leaders in terms of air pollution.

In large cities with large traffic flows, the content of carcinogenic substances of benzopyrene type in the air is 2-3 times, and in the centers of ferrous metallurgy about 12 times higher than in small cities or rural areas. Soil pollution in cities is mainly related to emissions from motor vehicles and industrial enterprises. Pollutants are accumulated or washed out by atmospheric precipitation from the air basin within a radius of $5 \mathrm{~km}$ from a stationary source of emissions.

The establishment of environmental management and regulation of environmental processes requires serious technical support and the use of modern technologies to solve problems related to environmental protection. For effective analysis and visualization of spatial information, there exist powerful tools - geographical information systems which not only allow you to create electronic maps based on databases, but also solve problems of any complexity due to the diverse analysis of available spatial information $[6,7]$.

Modern production, economic and other human activities are associated with the use of a huge amount of various substances, chemical compounds and other materials. This causes a significant burden on the environment, associated with a reduction in living space for untouched wildlife, penetration into the biosphere of substances unusual for their natural circulation, and a violation of the energy balance. The power of this load has reached such a level that it is quite capable of causing serious environmental crises and disasters [8].

Ukraine has significant land resources. As a result of irrational agricultural use, soils lose humus, they are polluted by chemicals, undergo water and wind erosion, are flooded, become salty, and plough land is reduced [9, $10]$.

The methodology and methodology of using geoinformation technologies in the performance of environmental monitoring is presented in scientific works [8-13].

\section{Outline of the basic material}

Currently, in the territory of Kharkiv and the region there are a number of environmental problems that cannot be resolved over the years and have an extremely negative impact on the environment. Kharkiv region ranks fifth in terms of industrial production and fifteenth in terms of generation and disposal of industrial toxic waste. The main contribution to air pollution is not made by enterprises (stationary sources of pollution), but by an ever-growing fleet of cars (mobile sources). And this significantly changes the whole map of air pollution in the city.

As a result of the analysis of pollution sources, the following were identified:

- Motor transport.

- Large enterprises - KhTP (KhTZ), CHPP-3 (TETs-3), CHPP-5 (TETs-5), Coke Plant (Koksokhimzavod).

It should be noted that the main pollutants that exceed the maximum allowable concentrations are dust, phenol, formaldehyde, carbon monoxide and soot. Other important factors of the unsatisfactory ecological state in the city are also a decrease in the number of green spaces, lack of sanitary zones of enterprises, natural features, poor management and poor environmental control.

An extremely important problem in the second most populous city of Ukraine is the problem of waste disposal:

- Lack of disposal of most components.

- Low control.

- Absence of private sector garbage collection system.

A vast scale of capital and housing construction, an increase in the population of Kharkiv, due to the dynamics of its development as an industrial and cultural center, led to a significant expansion of the city's borders. Currently, the city covers an area of $303 \mathrm{~km}^{2}$. Despite its large size, the city is characterized by compactness. A distinguishing characteristic of the city is that it is one of the greenest among the cities of that kind. Green areas of parks and gardens, boulevards and squares make up 12628 ha. There are more than $17 \mathrm{~m}^{2}$ of green space for one resident of the city.

The use of geographical information technologies makes it possible to visualize the available data on the contamination of the territory by this or that substance, to perform statistical analysis of the data, to study the distribution of data, to perform their transformation, to compare the existing state of pollution with the maximum allowable concentration.

Modern geoinformation systems, from developers such as: Spatial Manager, ActiveMap GS, GisMapServer, IndorCAD / River, MapInfo MapX, do 
not contain tools for monitoring indicators of air pollution by harmful substances, so there is a need to create software applications based on existing geographical information systems using modern methods of geostatistical analysis. A system for monitoring air pollution should allow modeling and analysis of polluted air flows.

In connection with the above, the importance of scientific, methodological and computer support for monitoring tasks, a comprehensive assessment of atmospheric pollution and determining the level of environmental risk for individual territories where modern geographical information technologies and geoinformation systems that provide spatial mapping of territorial objects in the form of electronic environmental maps, plays a decisive role.

The functional diagram of the developed geoinformation monitoring system consists of a data collection subsystem, a data storage subsystem based on geodatabase management systems, a data integration subsystem that allows you to analyze and visualize data using geoinformation and geostatistical methods; subsystems for publishing analysis results in the form of cartographic, tabular materials and reports.

Based on the statement of the problem, a local geographical information systems was developed, designed to assess the technogenic load of the air environment of the city of Kharkiv. Figure 1 shows the structure of this geographical information systems with respect to the direction of movement of accumulated data in the system.

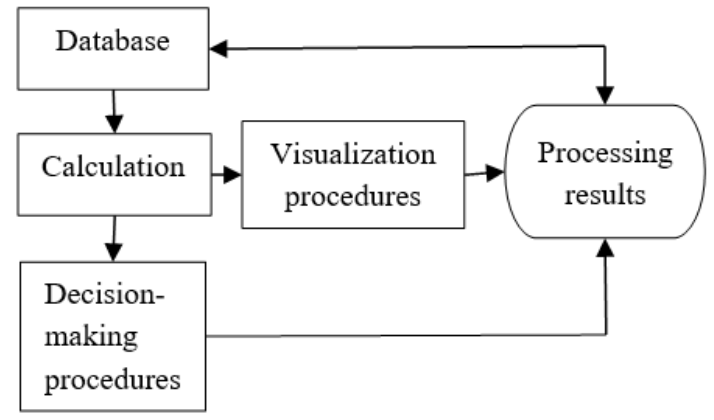

Fig. 1. The scheme of the developed geographic information system.

Using the database allows you to manage your data to edit and add new records. The system database collects atmospheric air pollution monitoring data for a specific area and is able to add new data and update old records if necessary. Also, the physical properties of pollution sources; maximum permissible harmful substances emissions; digitized terrain maps and substrate maps; data processing results using system procedures should be stored in the database of this monitoring geographical information systems.

Data is one of the most important components of geoinformation systems. Spatial data and related data can be updated with the required amount of time. In the process of spatial data management, geographical information systems integrates spatial data with other types of data, and uses the database to organize and store existing data.

According to the existing data collection system, statistical information describes in the most detailed and complete manner the volumes and locations of major sources of atmospheric emissions. To calculate air pollution in Kharkiv, we used statistical data on environmental emissions for the period $2015-2019$.

To display the objects of the city's industry, a personal geodatabase with the necessary layers was created [11]. The master plan of the city of Kharkiv, as amended in 2014, served as baseline data. As a result, a digital model of the territory of Kharkiv was made taking into account the number of enterprises - a darker color (Fig. 2)

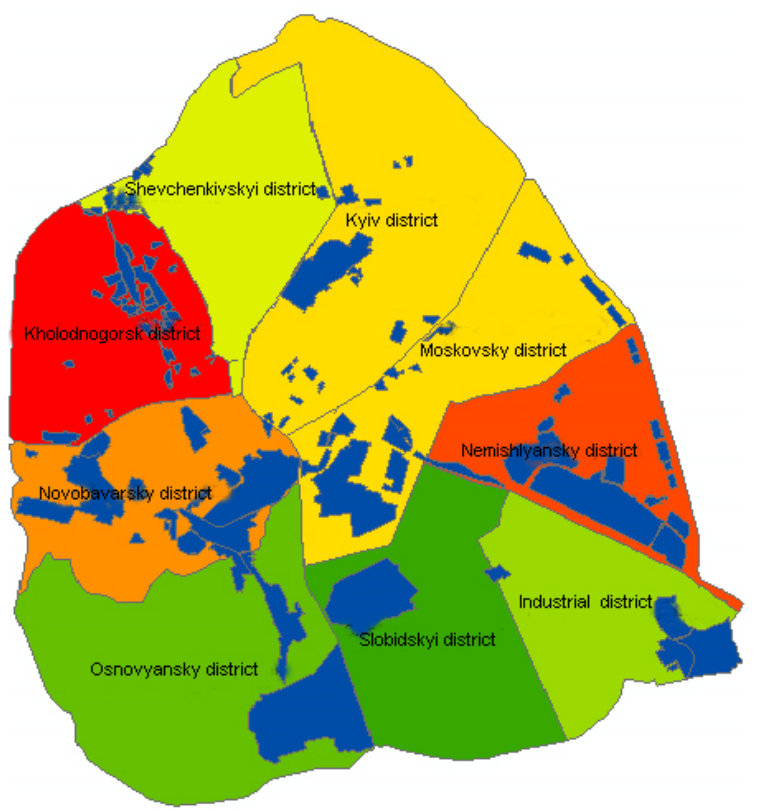

Fig. 2. Digital geoinformation model of the territory of Kharkiv.

The digital model shows that the main concentration of industrial enterprises (namely their share is the highest in pollution) is in Nemyshlianskyi, Kholodnohirskyi and Novobavarskyi districts of the city.

The attribute table of the "Contamination" layer was filled with data over the last five years (Fig. 3).

Having analyzed the amount of emissions of harmful substances into the atmosphere during this period, it was concluded that the amount of harmful substances as a whole is decreasing. The reason for the decrease in the amount of harmful substances in the atmosphere is due to the decrease in capacity in most large industrial enterprises. This conclusion illustrates the comparison of formaldehyde levels in the city air in 2019 (figure on the right) with 2015 (figure on the left) (Fig. 4).

The reasons for the continuing pollution of the atmosphere include the fact that not all operating enterprises which are sources of harmful emissions have built emission treatment facilities. One of the existing cleaning methods is the installation of cyclones (dry cleaning method). But it should be noted that this method of cleaning allows reducing harmful emissions 
to the permissible maximum allowable concentrations not in all cases. Only a few companies carry out regular production controls on the emissions and efficiency of treatment plants.

Also, the reason for the unsatisfactory state of the atmosphere is due to the fact that enterprises and organizations have got obsolete equipment that requires being repaired or replaced with a new one. One of the possible ways to reduce the technogenic load on the atmospheric air is closing outdated boiler houses and connecting heat consumers to boiler rooms equipped with modern treatment plants.

The created geographical information model made it possible to obtain histograms, clearly showing the pollutant emissions not only by types of harmful substances (Fig. 5), but also by industries which are the sources of these emissions. The figure shows the city's emission levels in 2018. It was also established that during this time interval the main enterprises that polluted the atmosphere were the "State Specialized Enterprise "Kharkiv State Interregional Special Combine" and the PJSC "Frunze Plant".

In 2015, the emissions of harmful substances were much higher (Fig. 6). The main enterprises from which these emissions were caused were State Enterprise "Malyshev Plant" ("Zavod im. Malysheva") and JSC "Turboatom".

\begin{tabular}{|c|c|c|c|c|c|c|c|c|c|c|}
\hline Name of company & Dust 2015 & Dust 2016 & Dust 2017 & Dust 2018 & Dust 2019 & Sulfur dioxide 2015 & Sulfur dioxide 2016 & Sulfur dioxide 2017 & Sulfur dioxide 2018 & Sulfur dioxide 2019 \\
\hline Urban wastewater treatment plants & \begin{tabular}{|l|}
0,6697 \\
\end{tabular} & 0,49 & \begin{tabular}{|r|}
0,59 \\
\end{tabular} & 0,7 & 0,89 & 0,7218 & \begin{tabular}{|r|}
0,4588 \\
\end{tabular} & 0,4502 & 0,2218 & 0,7128 \\
\hline Kharkiv Airport & 0,6525 & 0,49 & 0,59 & 0,7 & 0,88 & 0,7217 & 0,4666 & 0,4646 & 0,2227 & 0,7188 \\
\hline Ukrelektoremont factory & 0,6615 & 0,48 & 0,59 & 0,7 & 0,83 & 0,7219 & 0,4582 & 0,4535 & 0,3646 & 0,7181 \\
\hline Engineering factory & 0,6562 & 0,49 & 0,58 & 0,7 & 0,82 & 0,7241 & 0,4558 & 0,4638 & 0,2287 & 0,7244 \\
\hline Autogenous plant & 0,6644 & 0,49 & 0,58 & 0,7 & 0,93 & 0,7109 & 0,4692 & 0,4652 & 0,2295 & 0,7169 \\
\hline
\end{tabular}

Fig. 3. View of the fragment of the attribute table of the "Contamination" layer.
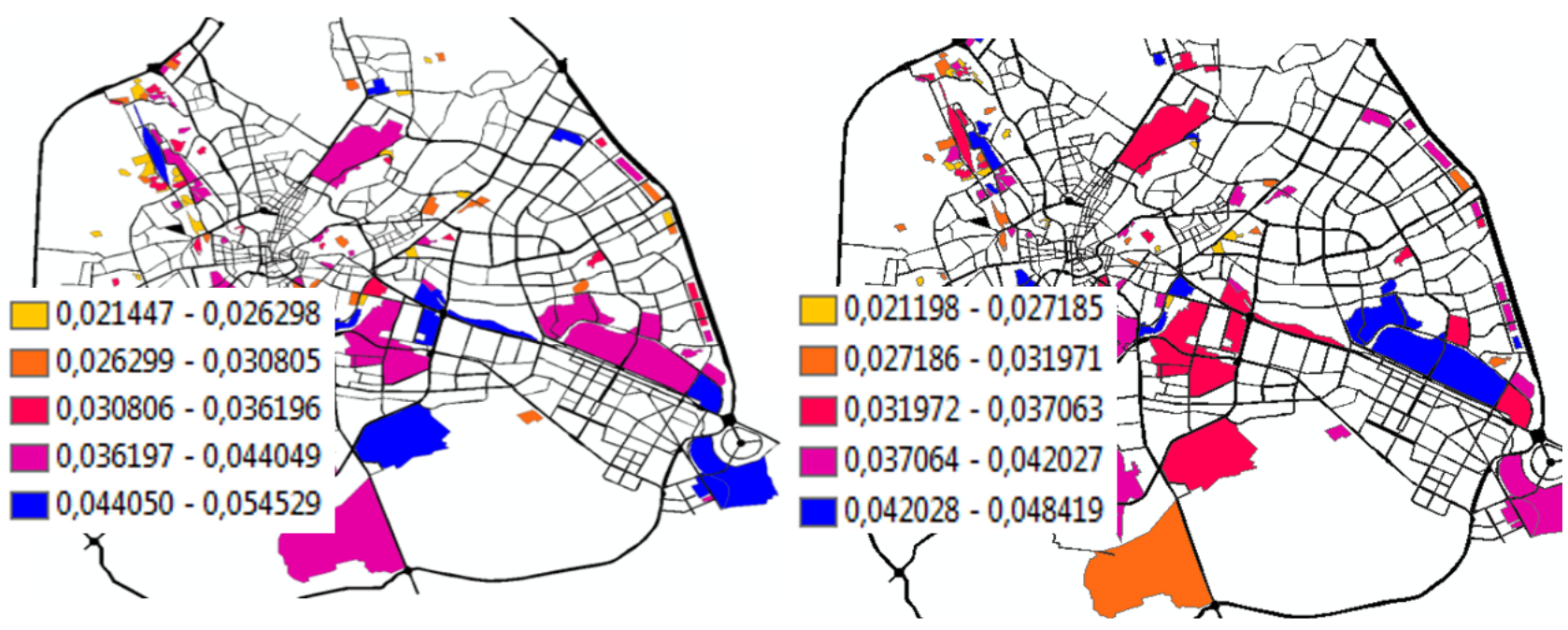

Fig. 4. The formaldehyde (mg/m) level in city air in 2015 in comparison with 2019.

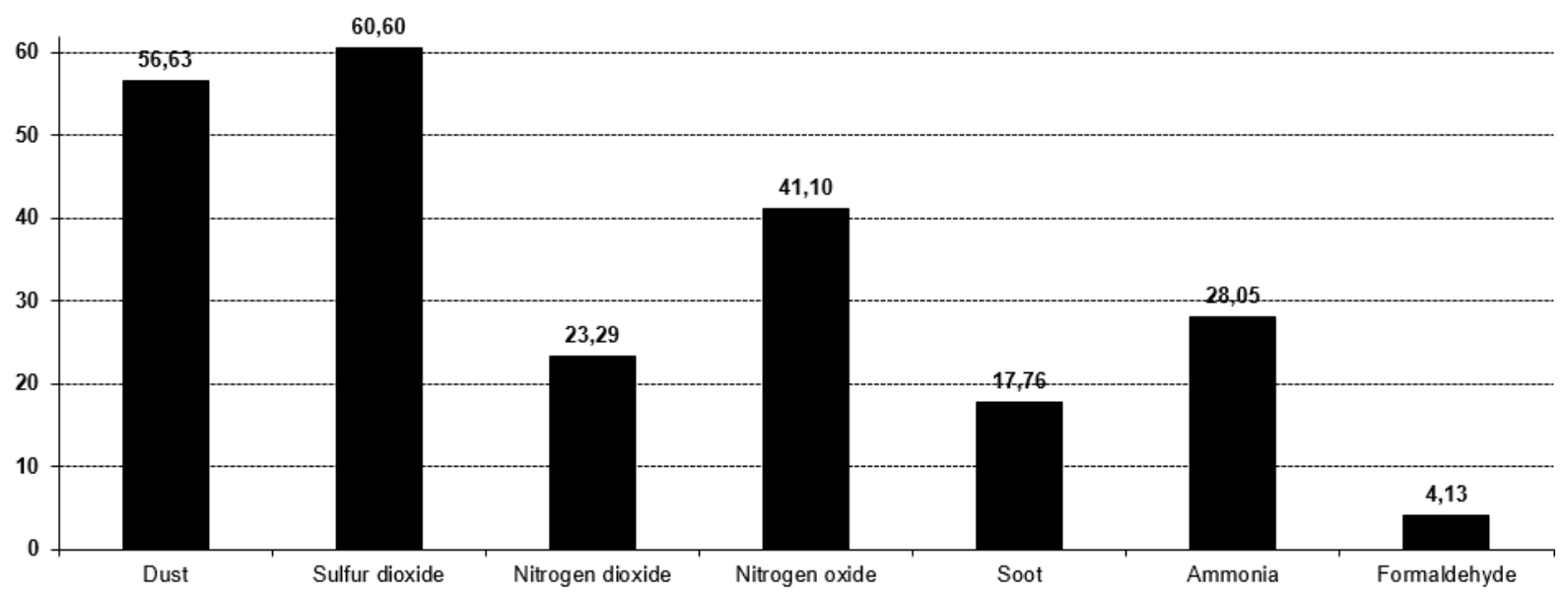

Fig. 5. Emissions of pollutants (thousand tons) into atmospheric air by types of harmful substances. 


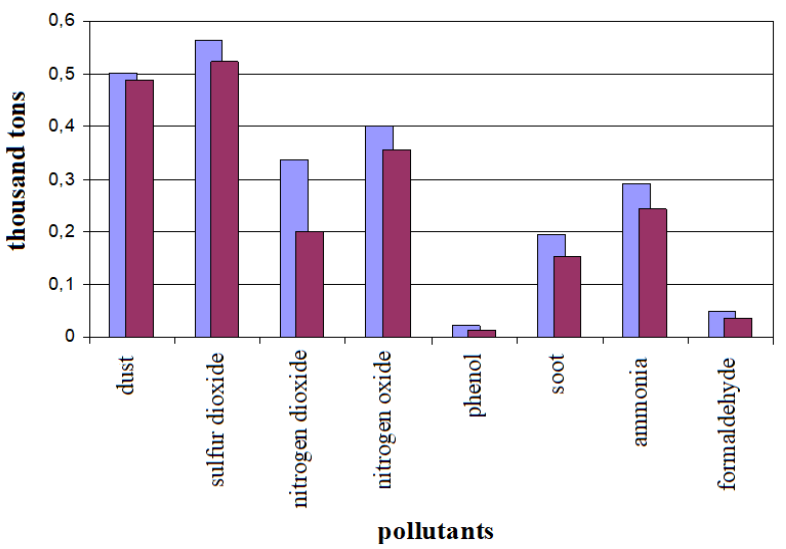

Fig. 6. Comparison of average emissions of pollutants in Kharkiv in 2015 and 2019

Assessment of the technogenic load on the environment, namely on the air environment, may be appropriate when using local geographical information systems map-based monitoring. Unpretentiousness to hardware costs, low cost of development and implementation, flexibility in designing, making amendments and improvements, the ability to build highprecision graphical models within local territories provides this type of geographical information systems advantages compared to a number of global systems existing and presented on the information market. Further development of this geographical information systems should be aimed at assessing, classifying the level of pollution, modeling the form and effects of pollution. For this, two indicators can be used - the air pollution index $(A P I)$ and the pollution index $(P I)$.

The air pollution index is used for the integral assessment of the condition of the air. This is a complex air pollution index which is calculated by the sum of several major pollutants when translating the absolute values of each into the maximum allowable concentration $(M A C)$. The conversion of absolute values into the air pollution index $(A P I)$ makes it possible to more effectively take into account the environmental damage caused by pollutants of various degrees of harmfulness.

According to state sanitary rules [14], all of the listed indicators have a specific algorithm and formulas for calculation. These formulas are presented below

$$
A P I=\sum_{i=1}^{n}\left(\frac{q_{i}}{M A C_{i M S}}\right)^{a_{i}}
$$

where $n$ - number of impurities taken into account in the calculation;

$$
q_{i} \text { - concentration of the } i \text {-th substance, } \mathrm{mg} / \mathrm{m}^{3} \text {; }
$$
$M A C_{i M S}$ is the maximum single MAC of the $i$-th substance, $\mathrm{mg} / \mathrm{m}^{3}$;

$a_{i}$ - the ratio of the hazard ratio of the $i$-th substance with the harmfulness of substance III hazard class $\left(a_{i}\right.$ of I class is $1.7, a_{i}$ of II class $-1.3, a_{i}$ of III class $-1.0, a_{i}$ of IV class -0.9$)$.

The assessment of the actual or predicted (estimated) level of air pollution is performed by comparing the index of pollution with one substance or the total pollution index $(\Sigma P I)$ with a mixture of substances with the maximum allowable pollution index $(M A P)$. A level not exceeding the MAP shall be considered admissible.

Indicator of maximum permissible atmospheric air pollution is a relative integral criterion for estimation of atmospheric air pollution of inhabited places, which characterizes the intensity and nature of the joint action of the whole set of polluting substances $(P S)$ present in it. $M A P$ is calculated for each case on the basis of experimentally determined and approved in the established order coefficients of combined action $\left(C_{C A}\right)$, which reflect the nature of the combined biological action of polluting substances (PS) simultaneously present in the atmospheric air. MAP is calculated by the formula:

$$
M A P=C_{C a} \cdot 100 \%
$$

Indicator of actual or predicted air pollution by one substance is calculated by the following formula:

$$
P I=\sum_{i=1}^{n}\left(\frac{C}{M A C}\right) \cdot 100 \%
$$

where $C$ - actual or predicted concentration of a specific substance, $\mathrm{mg} / \mathrm{m}^{3}$;

$M A C$ - maximum allowable concentration of this substance, $\mathrm{mg} / \mathrm{m}^{3}$.

Assessment of air pollution is carried out taking into account the rate of exceeding the $P I$ of their normative value $(M A C)$ and includes the determination of the level of pollution (permissible, unacceptable) and its degree of danger (safe, slightly dangerous, moderately dangerous, dangerous, very dangerous) [15].

Solving these problems, as well as supplementing the compute core of the system with decision-making and forecasting procedures, are the main areas of further development of the developed geographical information systems.

ArcGis software was used to determine the environmental situation of the city and build the electronic map. The environmental map reflected the spatial features of changes in the state of pollutant emission. The map made it possible to compare the state of environmental pollution by years. An ecological map was also created that provided the opportunity to link the geospatial distribution of industrial enterprises with certain types of pollutants. In contrast, for other pollutants, industrial areas are not a major factor. These findings allow regional managers to develop appropriate stabilization measures.

\section{Results}

1. A digital geographical information model of the Kharkiv city was developed, with a significant amount of attribute data input.

2. Calculations of maximum permissible indicators of pollutants in the atmosphere.

3. Models of comparison of formaldehyde in city air in 2015 with 2019 have been developed.

4. Models of comparison of pollutant emissions into the atmosphere based on monitoring results are developed. 


\section{Conclusions}

In the study, using the ArcGis software package, ecological models were developed and a map of the level of pollution with harmful substances in the city of Kharkiv was compiled. This map will provide an opportunity to set the necessary operating modes of polluting enterprises so that they do not harm the environment and the population. It will also allow regional leaders to make reasonable and correct decisions regarding environmental activities. The very principle of constructing ecological maps and database structure will be effective at any objects, so the developed geographical information systems can be distributed to any administrative units and industrial enterprises.

In general, an intelligent analysis of the geostatic models of the emissions distribution in a certain territory made it possible to identify and classify zones of high concentrations of pollution and compare them with data on air quality. To process statistical data in a single locality, geostatistical methods were used to transform data from a discrete to a continual representation. Further research in this direction may be related to the improvement of the geostatistical analysis of data and methods for predicting the distribution of pollution. As an example, mathematical formulas were presented to determine the atmospheric pollution index and the actual or predicted pollution index. These indicators can be determined on the basis of the data obtained in the study and presented using elements of the ArcGis software package in a discrete and continual form.

\section{References}

1. L.V. Mischenko, Dissertation, Yuriy Fedkovych Chernivtsi National University, 2003

2. S.P. Hansen, T.L. Messer, A.R. Mittelstet, Mitigating the risk of atrazine exposure: Identifying hot spots and hot times in surface waters across Nebraska. Journal of Environmental Management (2019). doi:10.1016/j.jenvman.2019.109424

3. S. Kobzan (ed.), Formation of the real estate market: practical aspects and features of the assessment (Urinkom Inter, Kiev, 2019)

4. M. Kavurmaci, A. Apaydin, Assessment of irrigation water quality by a geographic information System - Multicriteria decision analysis-based model. Water Environment Research 91(11) (2019). doi:10.1002/wer. 1133

5. H. Tahseenul, S.C. Vijay, M.A. Sanjay, A Forecasting tool for Air Quality Monitoring Built up on Cloud and IoT. International Journal of Innovative Technology and Exploring Engineering 8(10), 3821-3832 (2019)

6. F. Lisetckii, A. Borovlev, Monitoring of Emission of Particulate Matter and Air Pollution using Lidar in Belgorod, Russia. Aerosol and Air Quality Research 19, 504-515 (2019)
7. Q. Jia, Urban air quality assessment method based on GIS technology. Applied ecology and environmental research 17(4), 9367-9375 (2019)

8. A. El Aal, M. Kamel, A. Al-Homidy, Using remote sensing and GIS techniques in monitoring and mitigation of geohazards in Najran region. Geotechnical and Geological Engineering 37(5), 3673-3700 (2019). doi:10.1007/s10706-019-00861W

9. V.D. Pohrebennyk (ed.), Kompiuterni vymiriuvalnoinformatsiini systemy dlia operatyvnoho ekolohichnoho monitorynhu vodnoho seredovyshcha (Vydavnytstvo Lvivskoi politekhniky, Lviv, 2013)

10. N. Park, Y. Kim, B. Chang, G. Kwak, County-level indoor radon concentration mapping and uncertainty assessment in South Korea using geostatistical simulation and environmental factors. Journal of Environmental Radioactivity 208-209, 106044 (2019). doi:10.1016/j.jenvrad.2019.106044

11. Ya.F. Lomnytska (ed.), Sklad ta khimichnyi kontrol obiektiv dovkillia (Novyi Svit - 2000, Lviv, 2011)

12. R.M. Panas (ed.), Osnovy monitorynhu ta prohnozuvannia vykorystannia zemel (Novyi Svit 2000, Lviv, 2007)

13. O. Mititelu-Ionuş, D. Simulescu, S.M. Popescu, Environmental assessment of agricultural activities and groundwater nitrate pollution susceptibility: A regional case study. Environmental Monitoring and Assessment 191(8) (2019). doi:10.1007/s10661019-7648-0

14. Derzhavni sanitarni pravila ohoroni atmosfernogo povitrja naselenih mists' (vid zabrudnennja himichnimi ta biologichnimi rechovinami) (DSP201-97) (1997),

https://zakon.rada.gov.ua/rada/show/v020128297/ed20000223. Accessed 21 Mar 2020

15. A.V. Chuhai (ed.), Otsinka zabrudnenosti povitrianoho baseinu mista Mykolaiv. Ukrainskyi hidrometeorolohichnyi zhurnal 13 (2013)

16. V.H. Petruk, I.V. Vasylkivskyi (ed.), Normuvannia antropohennoho navantazhennia na navkolyshnie seredovyshche. Kursove proektuvannia (VNTU, Vinnytsia, 2015) 